\title{
THE TURNING POINT OF AN INTERNATIONAL INTERDISCIPLINARY PROGRAM
}

by

\author{
J. Henning Illies
}

\section{Scientific Basis for Future Cooperative Study}

The rapid progress made by the Geodynamics Project over the last decade and the flood of new ideas and publications emanating from it have provoked a lot of new questions, some contradictions and even criticism. This applies especially to the hypothesis now forming a crux in geological interpretation-plate tectonics. While the hypothesis offers an elegant explanatory framework for many of the observations made on the ocean floor, where divergent, convergent, and transform plate boundaries as discrete edges of moving plates are clearly defined, inland the precise nature of the plate tectonic model becomes more obscure.

For example, the Gibraltar-Azores plate boundary goes astray when entering the realm of the Mediterranean: is it the Periadriatic line of the Southern Alps where the African plate begins, or is it perhaps the Bavarian crust that collides along the Rif Atlas in Morocco? A zone of complex plate interaction separates Africa and Eurasia like a war of several fronts where the collision has shifted through geological time. And within this $1500 \mathrm{~km}$-wide megamylonite, hard inclusions are intercalated, acting as rigid microplates. Similarly, in China, shear zones with strong seismotectonic activity traverse the crust up to about $1200 \mathrm{~km}$ north of the collision front of the Himalayas. Even the classical plate boundary of San Andreas appears blurred if we look at parallel elements, like the Hayward or perhaps the Wasatch fault. Where is the western edge of "stable" North America?

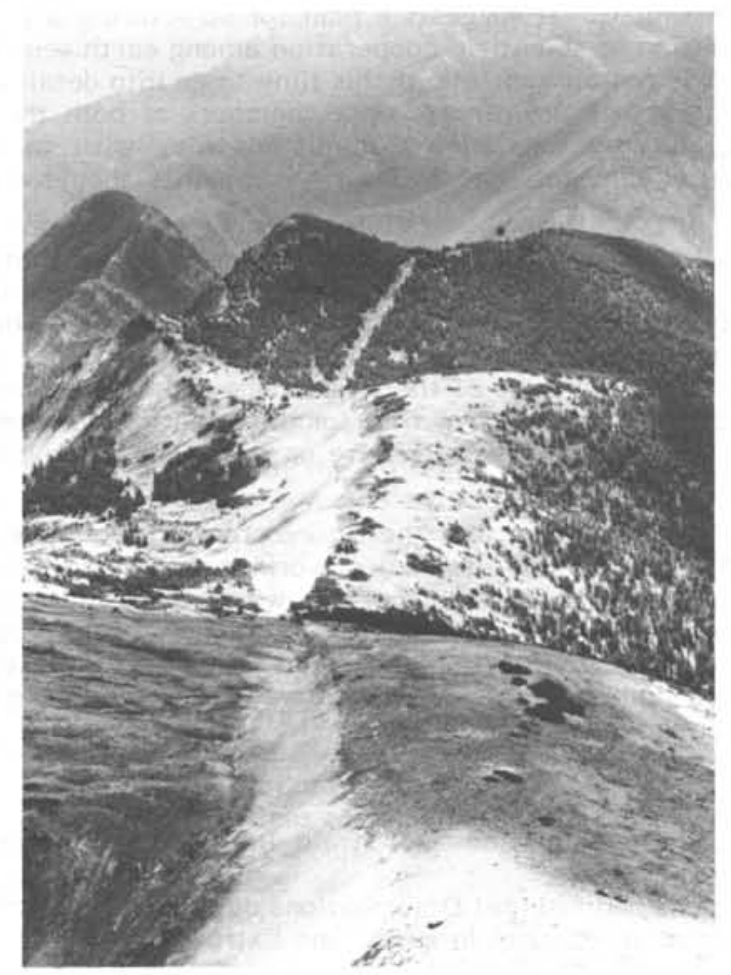

An example from NNW trending system of recent faults in western North America.
The regions we call forelands are often built up of extensive mosaics of unstable blocks which are pushed forward like ice floes in front of an ice-breaker. Holocene crustal movements and seismotectonic activity are observed as far north of the Alpine-Himalayan collision front as Netherlands in Europe and Lake Baikal in Asia. Are those distant effects plate or intraplate reactions, or perhaps both?

Contrary, then, to the distinct pattern of the ocean floor with its rifts, transform faults or trenches, the geological structure of the continental crust of ten looks like a page of untidy hieroglyphics. Every tectonic event has left its own marks, usually without totally effacing previously existing ones. A palimpsest of faults and folds, lineaments and joints, basins and plateaus was formed, making its geodynamic deciphering a complex and challenging task. Understandably, geologists mapping sheets or studying stratigraphy have sometimes had problems relating their observations to the hypothesis of plate tectonics.

Equally unclear are the interpretations ascribed to the most spectacular manifestations of current crustal unrest: earthquakes. It may often be observed that the seismic activity on fault systems shifts horizontally in time. Sometimes the behaviour of the affected crust resembles that of walls loosely built in stone, where cracks may suddenly appear in different places at different times. Earthquake prediction in such cases, includes the study of the geological structure, or, to carry the image further, the brickwork, mortar, and cracks of the wall that burst by tectonic stresses. But what constitutes the driving mechanism of tectonics? What is the influence of large-scale convection cells? Do they drive the lithospheric plates to collide, to diverge, or to transform? Why do these hypothesized cells, so deep-seated, manifest themselves in specific (subduction and rifting) zones? What enables such cells to follow features in the outer epidermis of the Earth when the plates move? Are deep-seated hot spots responsible for heat and magma generation under rift zones, or is it the influence of tensional fissure systems that provoked thermal fronts and upwelling magma to rise? While the kinematics of plate tectonics are well defined, more data is required before we can adequately define the dynamics and distinguish clearly between their causes and effects.

Even the causes of vertical movements, defined as epeirogeny in classical terms, remain essentially obscure. In the oceanic domain some interrelations have been identified between the relative elevation of the ocean floor, the age of the crust and its distance from the spreading centers. But the behaviour of the continental crust once again exhibits a higher complexity than that of the sea floor. Plateau uplift is often observed in larger foreland blocks in front of plate tectonic collision fronts. Was it shear heating at the base of the lithosphere that controlled such uplift and the commonly associated volcanic activity? Subsidence of basins and fault troughs, on the other hand, has apparently evolved in a manner independent of processes giving rise to heat flow anomalies, because many such basins demonstrate positive heat flow values. Sets of listric (shovel-like) dip-slip faults commonly penetrate the fill of those basins, leading to a thinning of the cover and perhaps a consequent oceanization of the underlying crust. 


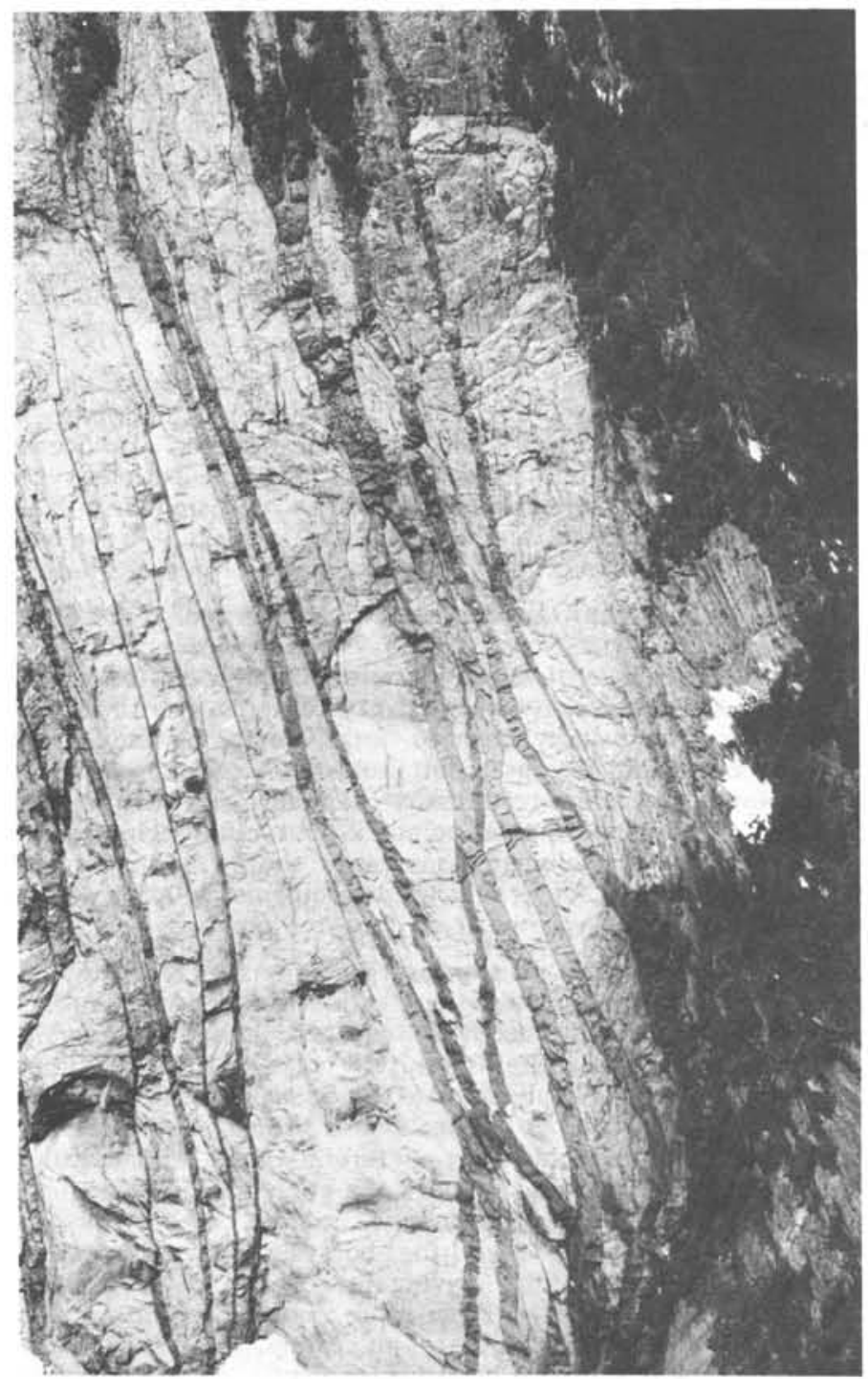

Former conduits for magma occupying a tensional fissure system in an epizonal granite body (cliff height: $500 \mathrm{~m}$ ).

To unravel the tangle of mutually interacting geological processes and their secondary effects, a promising technique has been applied and should be mentioned. In situ stress determinations by means of the overcoring and the hydrofracturing techniques reveal the nature of stresses in terms of their attitudes and magnitudes. Strain release may be defined by earthquakes, Holocene crustal deformations or geodetic measurements. Mapping both stress patterns and strain release on a regional scale illustrates where the stresses are generated, what excess stresses exist, and how they are consumed by creep or by earthquakes. This approach has made it possible to study active tectonic processes and, hopefully, delineate their causes and effects.

The limitations of the plate tectonic model outlined above have led to a number of major unresolved problems and form an obvious basis for future cooperative international research. With this in mind, and the fact that the Geodynamics Project, with its remarkable scientific achievements, is due to end by 1980, the International Union of Geological Sciences and the International Union of Geodesy and Geophysics agreed to examine the possibilities of implementing a new, well-designed, international, interdisciplinary program during the 1980's.
The Unions decided in 1977 to cooperate closely in discussing and planning a possible new program. Task groups were to be appointed by each Union and charged with the responsibility of preparing a detailed program for consideration by the Unions.

IUGS, taking advantage of the scientific expertise gathered in Paris in connection with the annual IGCP meetings, called a large informal meeting on February 19, 1978 to discuss and explore the possible emphases of a future program. Participants in this meeting agreed in principle on the need for a new program to cover the scope of continental and oceanic dynamics and to focus on themes where observed relationships did not fit current hypotheses. A task group, consisting of A.W. Bally (U.S.A.), V.V. Beloussov (U.S.S.R.), Y. Lancelot (France), C. Nishiwaki (Japan) and H. Illies (F.R.G.) as Convenor, was proposed to examine in full the scientific scope of such a program. By March, this group was "brainstorming" by letter, approaching different groups and individuals for input, proposing and debating a series of ideas and concepts.

In the meantime, IUGG had created a task group of its own, comprising C. Kisslinger (U.S.A.) as Convenor, P. Einarsson (Iceland) for IAVCEI, B. Naimark (U.S.S.R.) for IASPEI, D. Valencio (Argentina) for IAGA, P. Vyskocil (Czechoslovakia) for IAG. Both Unions felt that a truly effective planning effort required the task groups to meet jointly at least once; a working meeting for this purpose was held in Washington, D.C., from May 29 to June 1, 1978. (Since some task group members were unable to come to Washington, the following substitutes attended this meeting: M. Chinnery (U.S.A.) for IASPEI and S. Holdahl (U.S.A.) for IAG.)

Following the comprehensive discussions of the combined task groups, mostly on the role of the plate tectonic hypothesis as a basis for a future program, work was begun on an extensive document subsequently entitled "The Lithosphere: Frontier for the 1980's". This 90-page report, incorporating the views of all task group members, was edited by Dr. Kisslinger and submitted to the Executive Committees of both Unions. It suggests a plan for structuring a fruitful continuation of scientific cooperation among earth scientists. While it is not appropriate at this time to go into detail about the contents of the report, since members of both the task groups and the Executive Committees may wish to make substantial changes, the following comments should convey its general essence.

There was agreement among the task groups that "the crust" is too narrow a focus for a future program, even if one accepts the obvious implications that it is impossible to understand the crust without understanding the deeper shells of the Earth. In spite of the title of the report, we have not yet settled on a definitive title for the program, although the overall theme should concentrate on the origin and evolution of the lithosphere.

It was felt also that the future program should be built around a number of inter-union working groups to expedite the dialogue on topics and methods which are at the cutting edge of scientific progress in earth science. The proposed titles of these groups, their scope and terms of reference may form the skeleton of the future program. The working groups proposed include:

1. Stress in the Lithosphere

2. Uplift and Subsidence

3. Strain Accumulation and Strain Release in Tectonically Active Areas

4. Motions and Internal Deformations of Tectonic Plates

5. Magma Generation, Intrusion and Extrusion

6. Processes in the Earth's Interior

7. Mesozoic-Cenozoic Paleogeography and Paleoclimatology

8.-Pre-Mesozoic Tectonics 
9. Structure and Composition of the Lithosphere and Asthenosphere

10. Generation and Evolution of the Oceanic Lithosphere and the Ocean-Continent Transition Region

11. Generation and Evolution of Continental Lithosphere

12. Geodynamics of the Arctic.

Experience has shown that an organization supported by non-governmental bodies joined under the International Council of Scientific Unions (ICSU) constitutes a very satisfying mechanism for maintaining a program's required multinational interdisciplinary interaction. Should the proposed program be given approval by the Executive Committees of IUGS and IUGG and be endorsed by ICSU, it is anticipated that an Inter-Union Commission will then be established to operate this new scientific endeavour.
In concluding, I wish to express the sincere gratitude of my task group to the U.S. National Academy of Sciences for providing a grant through the Arthur L. Day Fund to partially support the joint task group meeting in Washington, and also to the staff of the NAS Geophysics Research Board (especially Dr. Pembroke Hart) for providing conference rooms and logistical assistance for the meeting. Special thanks are extended to Dr. Kisslinger for his efforts in arranging the meeting and for his help in editing "The Lithosphere: Frontier for the 1980's".
ABOUT THE AUTHOR: Dr. Henning Illies has held the chair in Geology at the University of Karlsruhe, Federal Republic of Germany, since 1958. He is wellknown internationally for his research work on the origin and evolution of the Rhine graben and other continental rifts.

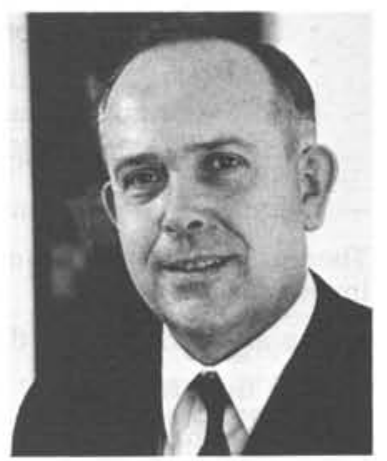

